CNME2010 - Congresso Nacional de Mecânica Experimental

Guimarães -21 a 23 de Abril de 2010

\title{
LONG DECK SUSPENSION BRIDGE MONITORING: THE VISION SYSTEM CALIBRATION PROBLEM
}

\author{
C.A. Santos ${ }^{1}$, C.O. Costa $^{2}$, J.P. Batista ${ }^{3}$ \\ ${ }^{1,2}$ Scientific Instrumentation Centre, National Laboratory for Civil Engineering \\ ${ }^{3}$ Department of Electrical Engineering and Computers, University of Coimbra
}

\begin{abstract}
The Structural Health Monitoring (SHM) is an emergent powerful diagnostic tool, which can be used to identify and to prevent possible failures of the various components that comprise the infrastructure. In the particular case of a suspension bridge, the measurement of the vertical and the transversal displacements plays an important role for its safety evaluation. Taking into account the restrictions usually found on these structures, an enhanced solution comprises a non-contact measurement system, specifically a vision-based measurement system. The paper describes a methodology to perform the vision system calibration which can be carried out in-situ, while the deck is moving, and requires little effort and a minimum set of information. Results related to the performance evaluation, obtained by simulation, are presented and they show that even in an environmental severely affected by noise it is possible to obtain a standard accuracy better than $10 \mathrm{~mm}$.
\end{abstract}

Keywords: Vision Metrology; Suspension Bridge; Displacements; Optical devices; Long range photogrammetry. 